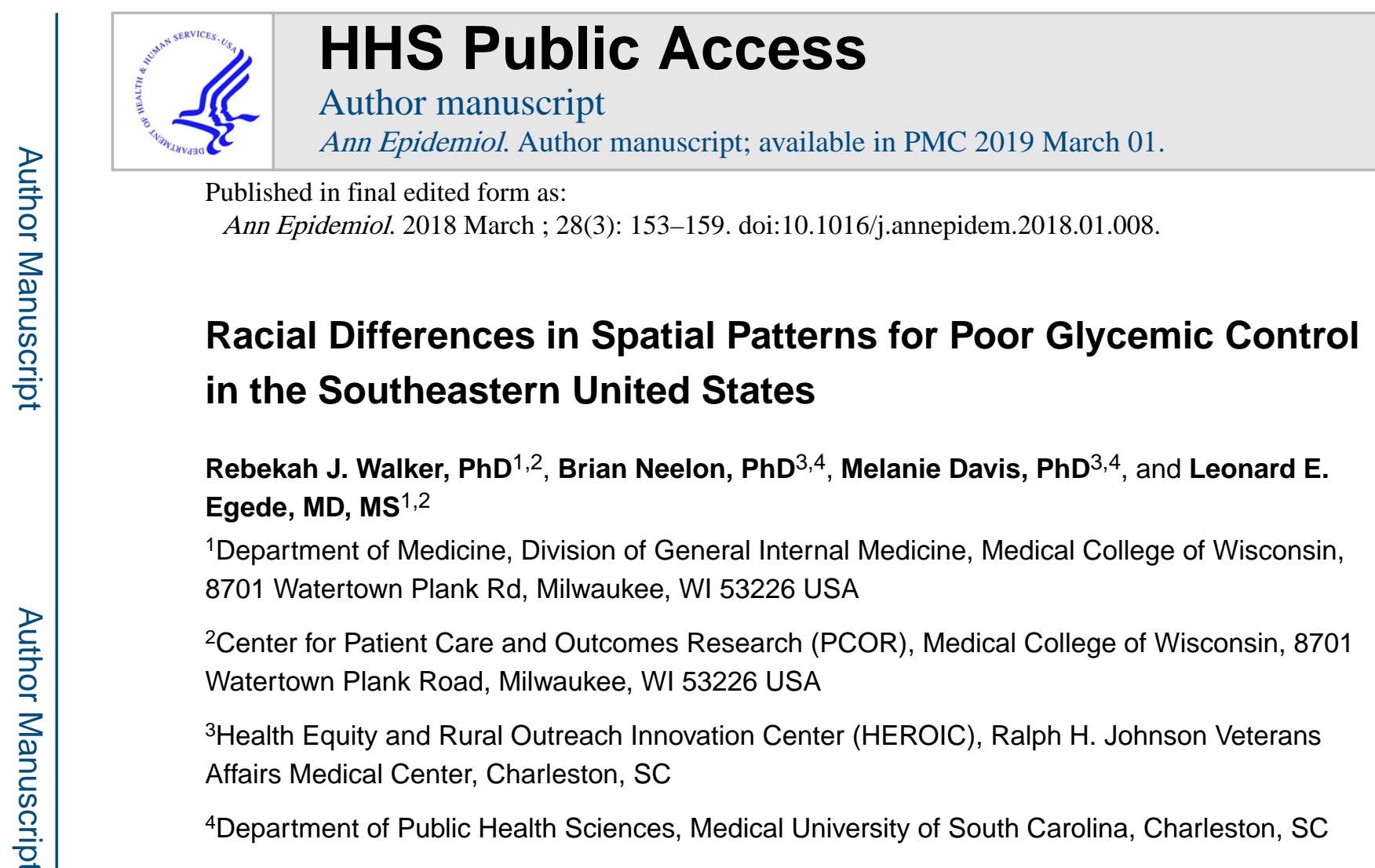

\begin{abstract}
Objective-Evidence consistently shows poor outcomes in racial minorities, but there is limited understanding of differences that are explained by spatial variation. The goal of this analysis was to examine contribution of spatial patterns on disparities in diabetes outcomes in the southeastern United States.
\end{abstract}

\begin{abstract}
Research Design and Methods-Data on 64,022 non-Hispanic Black (NHB) and nonHispanic White (NHW) Veterans with diabetes living in Georgia, Alabama, and South Carolina was analyzed for 2014. HbA1c was categorized as controlled ( $<8 \%$ and uncontrolled ( $>=8 \%)$. Logistic regression was used to understand the additional explanatory capability of spatial random effects over covariates such as demographics, service connectedness, and comorbidities. Data aggregated at the county level was used to identify hotspots in distribution of uncontrolled HbA1c and tested using local Moran's I test.
\end{abstract}

Results-Overall percent uncontrolled HbA1c was $36.5 \%$ (40.8\% in NHB and $33.4 \%$ in NHW). In unadjusted analyses, NHB had 37\% higher odds of uncontrolled HbA1c (OR: 1.37, 95\%CI $1.32,1.41)$. After adjusting for demographics and comorbidities the odds ratio decreased to 1.09 ,

Corresponding Author: Leonard E Egede, MD, MS, Department of Medicine, Division of General Internal Medicine, Medical College of Wisconsin, 8701 Watertown Plank Rd, Milwaukee, WI 53226 USA, Tel: 414-805-0840; Fax: 414-805-0855; legede@ mcw.edu.

Conflict of Interest: The authors report no competing financial interests exist.

Guarantors: LEE and BN are guarantors of the work.

Disclaimer: This article represents the views of the authors and not those of the VHA, or HSR\&D.

Author Contributions: LEE obtained funding for the study. RJW, MD, BN, and LEE designed the study, MD and BN analyzed the data, BN and LEE interpreted the results, RJW and MD drafted the article, and RJW, MD, BN, and LEE critically revised the manuscript for important intellectual content. All authors approved the final manuscript.

Publisher's Disclaimer: This is a PDF file of an unedited manuscript that has been accepted for publication. As a service to our customers we are providing this early version of the manuscript. The manuscript will undergo copyediting, typesetting, and review of the resulting proof before it is published in its final citable form. Please note that during the production process errors may be discovered which could affect the content, and all legal disclaimers that apply to the journal pertain. 
but remained significant $(95 \% \mathrm{CI} 1.05,1.13)$. The odds ratio further decreased after incorporating spatial effects (OR: 1.07, 95\% CI 1.03, 1.11), but remained statistically significant. Hotspots of high $\mathrm{HbA1c}$ were detected, and spatial patterns differed across racial groups.

Conclusions-Differences in spatial patterns in glycemic control exists between NHB and NHW Veterans with type 2 diabetes. Incorporating spatial effects helps explain more of the disparity in uncontrolled $\mathrm{HbA1c}$ than adjusting only for demographics and comorbidities, but significant differences in uncontrolled $\mathrm{HbA} 1 \mathrm{c}$ remained.

Diabetes is the seventh leading cause of death in the United States, and is associated with significant morbidity, mortality and health care utilization and cost, including among Veterans (1-4) Complications can be minimized and mortality lowered with improved glycemic control, however, national estimates suggest nearly half of those with diabetes do not meet national targets. $(5,6)$ Evidence consistently shows racial minorities have higher prevalence of diabetes, worse diabetes outcomes, higher risk of complications, worse glycemic control, and higher mortality rates compared to non-Hispanic whites (NHW), including an equal access system like the Veterans Health Administration (VA). (1,7-13)

Residential segregation is considered one of the fundamental causes of racial disparities in health, and patients with diabetes are particularly at risk for neighborhood influences because of the impact of social norms and values, physical attributes, and availability of resources on self-management behaviors necessary to maintain good glycemic control (1420). Most work on neighborhood influence, has focused on controlling for region or rural/ urban residence $(12,15,21-23)$. However, there is limited attention to how spatial patterns impact outcomes in diabetes. Spatial patterns can help in visualizing mismatch in healthcare supply and demand, as well as in determining areas with excess disease prevalence, to better elucidate the impact of residential segregation on health. (24-26) Therefore, use of methodologies that integrate spatial patterns, can help decision makers understand underlying patterns of disease attributable to environmental factors structurally determined by race, identify areas where organizational factors influence outcomes, and better plan health interventions tailored to local needs. (24-26)

Recent advances in Geographic Information Systems (GIS) to visualize patterns, and spatial analysis provide novel strategies to examine spatial variations, however, these novel tools are underutilized. $(24,27)$ Therefore, the goal of this analysis was to better understand the contribution of spatial patterns on disparities in diabetes outcomes in the southeastern United States.

\section{RESEARCH DESIGN AND METHODS}

\section{Data Source and Sample}

A national cohort of Veterans with type 2 diabetes was created using administrative data from the Veterans Health Administration (VHA). Veterans with two or more International Classification of Diseases Ninth Revision (ICD-9) codes for diabetes (250.xx) in either inpatient or outpatient visits in 2014 were retrieved. Individuals whose residential address was within the 272 counties in Georgia, Alabama, and South Carolina were selected for analysis. Race was derived using the patient race and ethnicity files and considered to be 
NHB if there was any record of indication of this category. For the purpose of this analysis, only NHB and NHW patients were selected. Laboratory values for HbA1c measures were linked using scrambled social security numbers. Individuals missing $\mathrm{HbA1c}$ values were not included in the analysis, resulting in a final sample size of 64,022 .

County was used as the unit of analysis for two reasons. First, from a policy standpoint, county was readily available in the electronic medical record and is the measure of location used to define VAMC catchment areas, therefore matching differences among patients who utilize the same healthcare facility. Policy decisions within the VA are likely to be made at a regional, rather than neighborhood level, and therefore, for the purposes of this VA-based analysis county level differences are reasonable to consider. Second, from a methodological standpoint to allow analysis of three states and maintain a reasonable number of spatial effects while fitting the model, county was an appropriate spatial unit.

\section{Study Variables}

The primary outcome variable was glycemic control (HbA1c) dichotomized as controlled $(<8 \%,<64 \mathrm{mmol} / \mathrm{mol}$ ) or uncontrolled ( $\ 8 \%, \varangle 64 \mathrm{mmol} / \mathrm{mol})$. A cutoff of $8 \%$ was chosen based on VA clinical guidelines. (28) Therefore, for the purposes of this analysis, Veterans with an $\mathrm{HbA1c}$ between $7 \%$ and $8 \%$, who would be considered not well controlled by American Diabetes Association guidelines were considered controlled by VA guidelines. $(28,29)$ The primary independent variable for logistic regression models was race dichotomized into NHB or NHW. Covariates included in adjusted analyses were age, gender, marital status, service-connected disability level, rural/urban residence, median household income, and comorbidities. Marital status was defined as married or single. Service connected disability was categorized as $<50 \%$ or $\geq 50 \%$, representing the cut-point for Veterans being exempted from co-payments for treatment at VA medical centers. Location of residence was categorized as urban, rural, or highly rural using RUCA codes. (30) Median household income at the county level was determined based on Census data and included to adjust for socioeconomic status. (31) Individual level income data was not available in the dataset. Comorbidities were based on ICD-9 codes and included substance abuse, anemia, cancer, cerebrovascular disease, congestive heart failure, cardiovascular disease, depression, hypertension, hyperthyroidism, liver disease, lung conditions, electrolyte disease, obesity, psychoses, peripheral vascular disease, and other diseases. (32)

\section{Statistical Analysis}

Three analyses were performed on individual level data: unadjusted, covariate adjusted, and covariate adjusted + spatial random effect analyses. For unadjusted analyses, we used a logistic regression model that regressed uncontrolled $\mathrm{HbAlc}$ on one variable (race).

Secondly, a similar model was fit including sociodemographic and comorbidity covariates. Third, we constructed a model that included the covariates of the second model but also incorporated a hierarchical spatial random effect for county. The spatial random effect was assigned a conditional autoregressive (CAR) prior in a Bayesian setting to allow for borrowing of information across adjacent counties and spatial "smoothing". The model was fit in R-INLA (www.r-inla.org), a package that allows for integrated nested Laplace approximation to derive posterior estimates in a Bayesian framework (33). 
Maps of the distribution of uncontrolled HbA1c aggregated at the county level were created using ESRI Geographic Information System. (34) To identify hotspots, a local Moran's I test was conducted (35). "High-high" hotspots were identified as neighboring counties with a positive standardized percent of uncontrolled A1c, a positive standardized spatial lag, and a significant local Moran's statistic. These areas represent localized clusters of above-average uncontrolled HBA1c. Likewise, "low-low" hotspots were identified as county clusters with a negative standardized percent of uncontrolled A1c, a negative standardized spatial lag, and a significant local Moran's statistic. These areas represent localized hotspots of controlled HbA1c. Analysis was run first on the full sample, and then by race to compare spatial patterns by NHB and NHW Veterans. Local Indicators of Spatial Association (LISA) maps were used to display information. (35) SAS was used to manage and aggregate data and R. 3.2.2 was used to compile maps. (36)

\section{RESULTS}

Sample sizes per county ranged from $n=5$ to $n=2409$ (mean $=235$, median $=108)$. Percent uncontrolled $\mathrm{HbA} 1 \mathrm{c}$ ranged from $18 \%$ to $100 \%$ across counties $($ mean $=37.74 \%$, median $=$ $37.36 \%$ ). Table 1 shows the baseline characteristics of the study subjects overall and by racial category. Differences existed in rural/urban residence with $70.3 \%$ of NHB living in urban areas, compared to $52.2 \%$ of NHW. Overall percent uncontrolled HbA1c defined as HbA1c $28 \%$ was 36.5 (40.8\% in NHB and $33.4 \%$ in NHW).

Table 2 shows the unadjusted, covariate adjusted, and covariate plus spatially adjusted odds ratios. In unadjusted analyses, NHB had 37\% higher odds of uncontrolled HbA1c (OR: 1.37, $95 \%$ CI 1.32, 1.41). After adjusting for demographics and comorbidities the odds ratio decreased to 1.09 , but remained significant $(95 \%$ CI $1.05,1.13)$. The odds ratio further decreased after incorporating spatial effects (OR: 1.07, 95\% CI 1.03, 1.11), but remained statistically significant.

Figure 1 shows the maps of percent uncontrolled diabetes and Figure 2 shows the LISA maps indicating hotspots of uncontrolled diabetes. Maps indicate different spatial patterns for NHW and NHB Veterans. It is important to note that hotspots do not represent a comparison of severity in poor control between the NHW and NHB Veterans, but instead show hotspots among NHW and hotspots among NHB indicating the location of hotspots differs for the two groups.

\section{CONCLUSION}

Using a sample of Veterans from three southeastern states, this analysis showed the importance of considering spatial patterns when investigating racial differences in diabetes outcomes. Inclusion of the spatial random effect indicates that spatial variation explains additional differences in uncontrolled diabetes between NHB and NHW patients beyond the standard sociodemographic and comorbidity covariates used in most analyses. In addition, mapping hotspots by race found differences in spatial patterns by race.

This study is one of the first of its kind, incorporating spatial effects to help explain more of the disparity in uncontrolled $\mathrm{HbA} 1 \mathrm{c}$ in patients with diabetes beyond adjusting only for 
demographics and comorbidities. Inclusion of spatial variation decreased the disparity between NHB and NHW Veterans, but the relationship remained significant after inclusion, suggesting that additional differences exist. Given the VA provides a more equal access environment than the overall US healthcare system, the additional explanatory capabilities of spatial variation highlights the importance of considering the factors outside the healthcare system and their influence on health outcomes. Poor health and health behaviors have historically been considered a function of poor environments, with little effort to understand how the healthcare system can address the racially/ethnically disparate outcomes that result. $(14,15)$ Understanding availability of resources in surrounding environments, such as location of healthcare facilities, and availability of healthy food options or places to exercise are important components for future research. Creation of georeferenced data layers with locations of resources mapped in relation to outcomes would allow analysis to better understand reasons for spatial variation, and would help guide policy decisions. The modest change in racial differences after incorporating spatial effects may be a result of analysis at the county level, and therefore a finer spatial unit may be necessary for future analyses, particularly to understand neighborhood level influences. This county level analysis, however, is important for consideration of VA policies to ensure equitable access for Veterans across catchment areas. Hotspots of poor outcomes should be investigated in more detail to ensure access to healthcare facilities and availability of resources.

An additional finding is highlighting the flaw in assuming hotspots for poor outcomes is similar across racial groups. In fact, in this population hotspots for poor glycemic control differed by race, suggesting interventions to decrease disparities must take these differences into account, targeting the particular subpopulation and the underlying reason for those differences. Further analyses, joint modeling health outcomes with additional layers of information, such as healthcare utilization or neighborhood level socioeconomic status, can help elucidate spatial connections not previously understood and inform more targeted interventions. By selecting specific hotspots that differ by race, state and local programs can work to determine reasons for the increased risk in the particular county, and develop interventions that target the needs of those communities, rather than disseminating a general program across multiple counties that may face different drivers of risk. Additionally, more detailed information on socioeconomic status to help explain differences driven by income. Hotspot differences by race may be explained by finer detail residential segregation and structural processes that shape local environments or may be a result of limited resources in a specific county. Therefore, these results warrant more detailed analysis within each hotspot to improve outcomes at the local level.

The importance of geography in healthcare was comprehensively demonstrated through the release of results from the Dartmouth Atlas of Health Care. (37) Analyses conducted in the US show spatial variation in diabetes prevalence and differential risk across regions for modifiable risk factors. $(22,24-26,38)$ Recent analyses of national US data showed the relationship between diabetes prevalence and predictors such as poverty, education, and obesity, varied by space as opposed to a global predictor of prevalence. $(26,39)$ In addition, variation in diabetes outcomes has been noted at the facility level in the VA $(40,41)$, but this is one of the first studies to use advanced spatial methods to assess geographic variation in diabetes-related disparities across a large geographic region. The use of hotspot analysis 
overall, and by predisposing risk factors, such as race, is an important next step in providing more personalized and targeted interventions to improve health outcomes. An important next step would be creation of georeferenced data layers for both VA and non-VA hospital and clinic locations. Inclusion of data layers explaining spatial variation in healthcare access may help direct future resource allocation.

While this innovative methodology and the comprehensive dataset available in the VA dataset were strengths of this study, there are some limitations worth mentioning. First, generalization of these results may be limited to Veteran populations. A recent study, however, did suggest results of Veteran analyses may be more broadly representative of Medicare populations based on the age and comorbidity load. (42) Secondly, additional factors not included in these models should be considered in future work to help explain racial differences, including community resources and distance to healthcare locations. Individual household income would be an additional variable important to consider in future analyses. Finally, these results are based on one year of data and may not be representative of outcomes during other years, though the general trends in the US suggest poor diabetes outcomes continues to be a major public health issue. Future work could employ spatiotemporal models to examine changing spatial patterns over time. (43) Additionally, more localized spatial analyses could be conducted within hotspots to capture localized neighborhood effects.

In conclusion, using traditional regression analysis incorporating spatial effects, and mapping of spatial patterns by race, we found differences in spatial patterns in glycemic control between NHB and NHW Veterans with type 2 diabetes. Incorporating spatial effects helped explain more of the disparity in uncontrolled $\mathrm{HbA1c}$ than adjusting only for demographics and comorbidities, but remained significant indicating additional differences persist. Hotspots for poor outcomes differed by racial group, suggesting the need for targeted interventions to better address the factors driving these differences at the local level.

\section{Acknowledgments}

Funding Source: This study was supported by Grant \# VA HSR\&D HX001229, Charleston VA Health Equity and Rural Outreach Innovation Center, supported by the VA Health Services Research and Development (PI: Leonard Egede).

\section{References}

1. Center for Disease Control and Prevention (CDC). National Diabetes Statistics Report: Estimates of Diabetes and Its Burden in the United States. Atlanta, GA: US Department of Health and Human Services; 2014.

2. Egede LE, Ellis C. Diabetes and depression: global perspectives. Diab Res Clin Pract. 2010; 87(3): 302-312.

3. Miller DR, Safford MM, Pogach LM. Who has diabetes? Best estimates of diabetes prevalence in the Department of Veterans Affairs based on computerized patient data. Diabetes Care. 2004; 27:B10-21. [PubMed: 15113777]

4. Wahowiak L. Veterans and Diabetes: the VA's focus on diabetes care, research, and training. Diabetes Forecast. 2014; 67(12):44-47.

5. Ali MK, Bullard KM, Gregg EW. Achievement of goals in US diabetes care: 1999-2010. N Engl J Med. 2013; 369(3):287-288. 
6. Shalev V, Chodick G, Bialik M, Green MS, Heymann AD. In a population-based cohort of diabetes patients, men and women had similar risks for all-cause mortality. J Clin Epidemiol. 2007; 60(1): 86-93. [PubMed: 17161759]

7. Egede LE, Dagogo-Jack S. Epidemiology of type 2 diabetes: focus on ethnic minorities. Med Clin North Am. 2005; 89(5):949-975. [PubMed: 16129107]

8. Campbell JA, Walker RJ, Smalls BL, Egede LE. Glucose control in diabetes: the impact of racial differences on monitoring and outcomes. Endocrine. 2012; 42(3):471-482. [PubMed: 22815042]

9. Kirk JK, D’Agostino RB Jr, Bell RA, Passmore LV, Bonds DE, Karter AJ, Narayan KM. Disparities in $\mathrm{HbA} 1 \mathrm{c}$ levels between African-American and non-Hispanic white adults with diabetes: a metaanalysis. Diabetes Care. 2006; 29(9):2130-6. [PubMed: 16936167]

10. Egede LE, Mueller M, Echols CL, Gebregziabher M. Longitudinal differences in glycemic control by race/ethnicity among veterans with type 2 diabetes. Med Care. 2010; 48(6):527-533. [PubMed: 20473215]

11. Hunt KJ, Gebregziabher M, Lynch CP, Echols C, Mauldin PD, Egede LE. Impact of diabetes control on mortality by race in a national cohort of veterans. Ann Epidemiol. 2013; 23(2):74-79. [PubMed: 23238350]

12. Egede LE, Gebregziabher M, Hunt KJ, et al. Regional, geographic, and racial/ethnic variation in glycemic control in a national sample of veterans with diabetes. Diabetes Care. 2011;34(4):938943. [PubMed: 21335370]

13. Walker RJ, Williams JS, Egede LE. Influence of race, ethnicity, and social determinants of health on diabetes outcomes. Am J Med Sciences. 2016; 351(4):366-373.

14. Williams DR, Collins C. Racial residential segregation: a fundamental cause of racial disparities in health. Public Health Reports. 2001; 116:404-416. [PubMed: 12042604]

15. Landrine H, Corral I. Separate and unequal: residential segregation and black health disparities. Ethnicity \& Disease. 2009; 19:179-184. [PubMed: 19537230]

16. Diez Roux AV, Mair C. Neighborhoods and health. Ann NY Acad Sci. 2010; 1186:125-45. [PubMed: 20201871]

17. Karasek D, Ahern J, Galea S. Social norms, collective efficacy, and smoking cessation in urban neighborhoods. Am J Public Health. 2012; 102:343-51. [PubMed: 22390449]

18. Shootman M, Andersen EM, Wolinsky FD, Malmstrom TK, Miller JP, Yan Y, Miller DK. The effect of adverse housing and neighborhood conditions on the development of diabetes mellitus among middle-aged African Americans. Am J Epi. 2007; 166:379-387.

19. Cox M, Boyle PJ, Davey PG, Feng Z, Morris AD. Locality deprivation and type 2 diabetes incidence; a local test of relative inequalities. Soc Sci Med. 2007; 65:1953-1964. [PubMed: 17719709]

20. Laraia BA, Karter AJ, Warton EM, Schillinger D, et al. Place matters: neighborhood deprivation and cardiometabolic risk factors in the DISTANCE study. Soc Sci Med. 2012; 74(7):1082-1090. [PubMed: 22373821]

21. Egede LE, Gebregziabher M, Hunt KJ, et al. Regional, Geographic, and Ethnic Differences in Medication Adherence Among Adults with Type 2 Diabetes. Ann Pharmacother. 2011c; 45(2): 169-178. [PubMed: 21304026]

22. Dwyer-Lindgren L, Mackenbach JP, vanLenthe FJ, Flaxman AD, Mokdad AH. Diagnosed and undiagnosed diabetes prevalence by county in the US, 1999-2012. Diabetes Care. 2016; 39:15561562. [PubMed: 27555622]

23. Puckrein GA, Egan BM, Howard G. Social and medical determinants of cardiometabolic health: the big picture. Ethnicity \& Disease. 2015; 25(4):521-524. [PubMed: 26673674]

24. Baker J, White N, Mengersen K. Missing in space: an evaluation of imputation methods for missing data in spatial analysis of risk factors for type II diabetes. Int J Health Geogr. 2014; 13:47. [PubMed: 25410053]

25. Dijkstra A, Hak E, Janssen F. A systematic review of the application of spatial analysis in pharmacoepidemiologic research. Ann Epidemiol. 2013; 23(8):504-14. [PubMed: 23830932]

26. Siordia C, Saenz J, Tom SE. An introduction to macro-level spatial nonstationarity: a geographically weighted regression analysis of diabetes and poverty. Human Geog. 2012; 6(2):513. 
27. Shaw N. Geographical information systems and health: current state and future directions. Healthcare Informatics Res. 2012; 18(2):88-96.

28. VA/DoD Clinical Practice Guidelines. 2017. Available at: https://www.healthquality.va.gov/ guidelines/cd/diabetes/

29. American Diabetes Association. Standards of Medical Care in Diabetes - 2018. Diabetes Care. 2018 Jan; 41(Supplement 1):S1-S2. [PubMed: 29222369]

30. West AN, Lee RE, Shambaugh-Miller MD, Bair BD, Mueller KJ, et al. Defining "rural" for veterans' health care planning. J Rural Health. 2010; 26(4):301-309. [PubMed: 21029164]

31. U.S. Census Bureau; American Community Survey. American Community Survey 1-Year Estimates, Table B19013. 2014.

32. Quan H, Sundararajan V, Halfon P, Fong A, Burnand B, Luthi JC, Saunders LD, Beck CA, Feasby TE, Ghali WA. Coding algorithms for defining comorbidities in ICD-9-CM and ICD-10 administrative data. Med Care. 2005; 43:1130-1139. [PubMed: 16224307]

33. Rue H, Martino S, Chopin N. Approximate Bayesian inference for latent Gaussian models using integrated nested Laplace approximations. Journal of the Royal Statistical Society. 2009; 71(2): 319-392.

34. ESRI. ArcGIS Desktop: Release 10. Redlands, CA: Environmental Systems Research Institute; 2011.

35. Anselin L. Local Indicators of Spatial Association-LISA. Geographical Analysis. 1995; 27:93115.

36. R Core Team. R: A language and environment for statistical computing. R Foundation for Statistical Computing; Vienna, Austria: 2015.

37. Cooper MM. The Dartmouth Atlas of Health Care: what is it telling us? Health Syst Rev. 1996; 29(3):44-5. [PubMed: 10158559]

38. Noble D, Smith D, Mathur R, Robson J, Greenhalgh T. Feasibility study of geospatial mapping of chronic disease risk to inform public health commissioning. BMJ Open. 2012; 2(1):e000711.doi: 10.1136/bmjopen-2011-000711

39. Hipp JA, Chalise N. Spatial analysis and correlates of county-level diabetes prevalence, 20092010. Prev Chronic Dis. 2015 Jan 22.12:E08.doi: 10.58888/pcd12.140404 [PubMed: 25611797]

40. Thompson W, Wang H, Xie M, et al. Assessing quality of diabetes care by measuring longitudinal changes in hemoglobin A1c in the Veterans Health Administration. Health Serv Res. 2005; 40(6): 1818-35. [PubMed: 16336550]

41. Krein SL, Hofer TP, Kerr EA, Hayward RA. Whom should we profile? Examining diabetes care practice variation among primary care providers, provider groups and health care facilities. Health Serv Res. 2002; 37(5):1159-80. [PubMed: 12479491]

42. Wong ES, Wang V, Liu C, Hebert PL, Maciejewski ML. Do Veterans Health Administration Enrollees Generalize to Other Populations? Med Care Res and Review. 2016; 73(4):493-507.

43. Banerjee, S., Carlin, BP., Gelfand, AE. Hierarchical modeling and analysis for spatial data. 2. Chapman and Hall/CRC Press; Boca Raton, FL: 2014. 


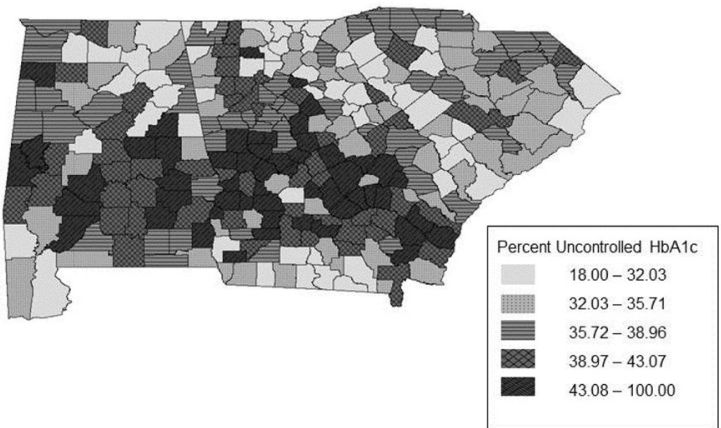

Full Sample
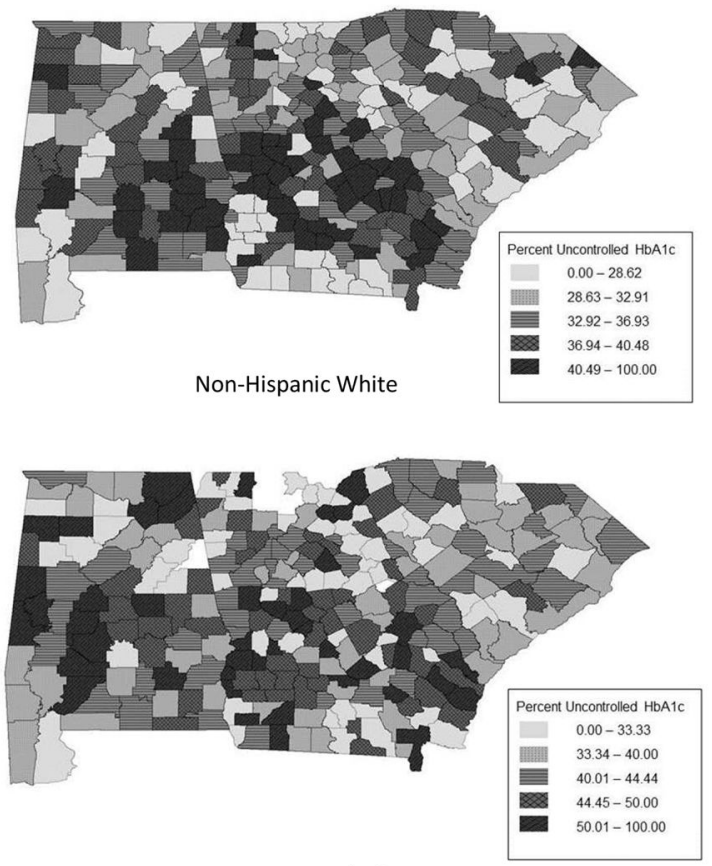

Non-Hispanic Black

Figure 1.

Map of percent quantiles of uncontrolled diabetes (defined as HbA1c 28 ) among Veterans with diabetes in the southeastern United States in 2014. Lightest shaded counties represent lowest quartile, with increasing darkness as \% uncontrolled A1c in county increases. 

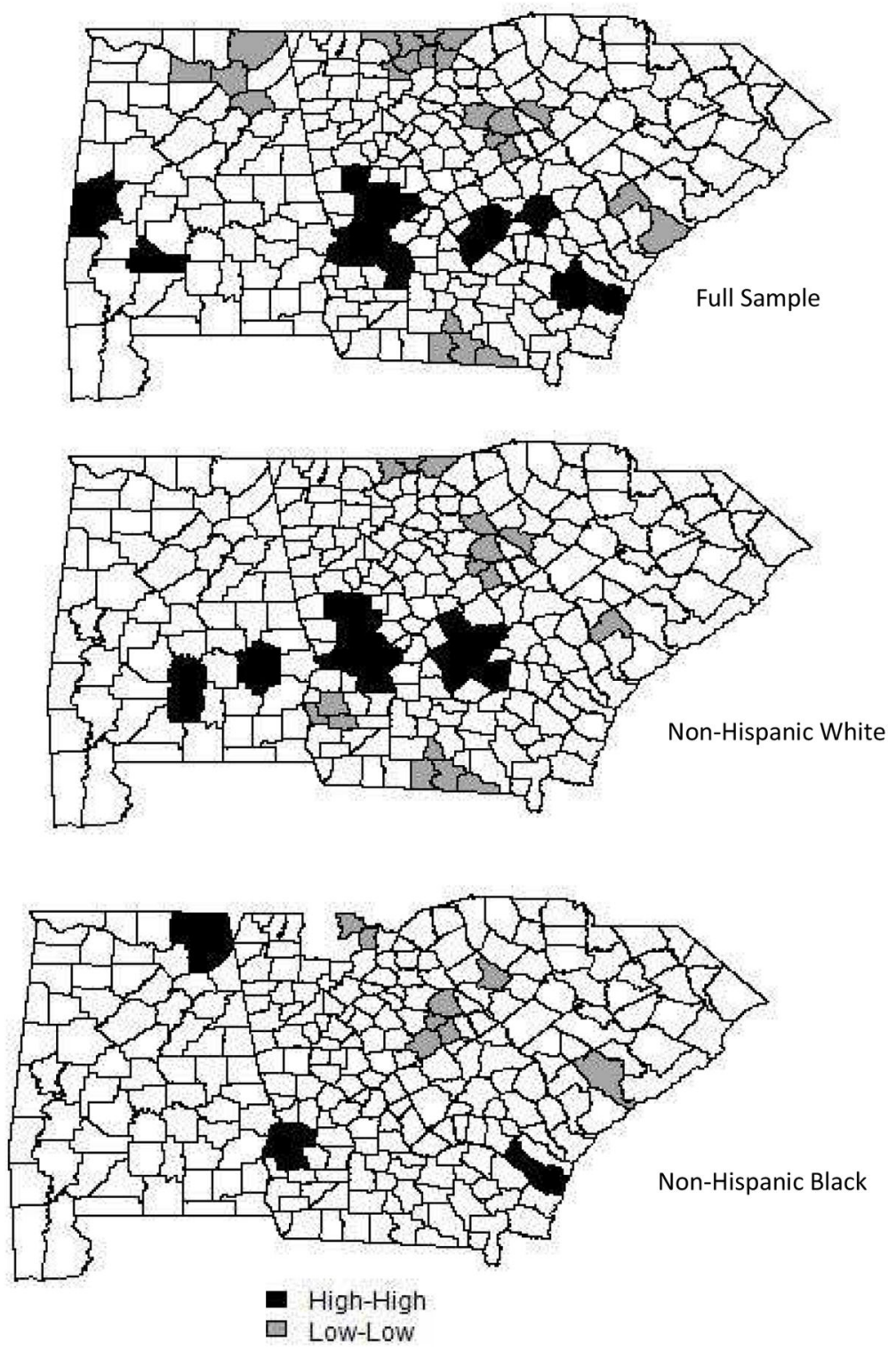

Figure 2.

Local Indicators of Spatial Association (LISA) map indicating hotspots of uncontrolled diabetes among Veterans with diabetes in the southeastern United States in 2014. High-high: county has a high number of uncontrolled A1c and is bordered by other high A1c counties. These areas can be interpreted as hotspots of uncontrolled A1c. Low-low: county has a low number of uncontrolled A1c and is bordered by other low A1c counties. These areas can be interpreted as hotspots of controlled A1c. 
Table 1

Sample Demographics

\begin{tabular}{|c|c|c|c|}
\hline \multirow[t]{2}{*}{ Variable } & \multicolumn{3}{|l|}{ Percent } \\
\hline & Overall $(n=64,022)$ & NHB $(n=25,808)$ & NHW $(n=38,214)$ \\
\hline Age (mean years, $(\mathrm{sd}))$ & $67.64(10.04)$ & $64.21(9.89)$ & $69.96(9.40)$ \\
\hline Uncontrolled A1C & 36.49 & 40.83 & 33.45 \\
\hline Male & 95.82 & 93.21 & 97.59 \\
\hline NHB & 40.31 & & \\
\hline Service Connectedness & 40.51 & 46.74 & 36.31 \\
\hline Married & 62.99 & 54.86 & 68.49 \\
\hline \multicolumn{4}{|l|}{ RUCA } \\
\hline Urban & 59.47 & 70.31 & 52.15 \\
\hline Rural & 39.74 & 29.23 & 46.83 \\
\hline Highly Rural & 0.76 & 0.43 & 0.98 \\
\hline Household Income for County (median \$, (sd)) & $\$ 45,270.16(\$ 9,654.63)$ & $\$ 45,270.16(\$ 9,654.63)$ & $\$ 45,270.16(\$ 9,654.63)$ \\
\hline Substance abuse (AA or DA) & 6.89 & 10.52 & 4.43 \\
\hline Anemia & 3.34 & 3.60 & 3.16 \\
\hline Cancer & 2.87 & 2.79 & 2.92 \\
\hline Cerebrovascular disease & 3.97 & 4.16 & 3.83 \\
\hline Congestive heart failure & 9.00 & 8.50 & 9.34 \\
\hline Cardiovascular disease & 13.39 & 9.14 & 16.26 \\
\hline Depression & 30.84 & 34.68 & 26.24 \\
\hline Hypertension & 84.21 & 87.12 & 82.24 \\
\hline Hypothyroidism & 8.24 & 4.63 & 10.67 \\
\hline Liver Disease & 3.34 & 3.95 & 2.92 \\
\hline Lung conditions & 15.96 & 12.62 & 18.21 \\
\hline Electrolyte diseases & 5.15 & 6.15 & 4.47 \\
\hline Obesity & 21.70 & 23.73 & 20.33 \\
\hline Psychoses & 5.08 & 7.54 & 3.41 \\
\hline Peripheral vascular disease & 7.99 & 6.78 & 8.80 \\
\hline Other disease & 18.34 & 21.39 & 16.28 \\
\hline
\end{tabular}


吝

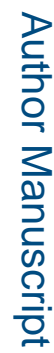

\begin{tabular}{|c|c|c|c|c|c|c|c|c|c|c|c|c|c|c|c|c|c|c|c|c|c|c|c|c|c|}
\hline & $\begin{array}{l}\bar{U} \\
\therefore \\
2 \\
2\end{array}$ & $\exists$ & 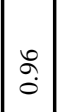 & $\stackrel{d}{\stackrel{d}{a}}$ & बे & $\stackrel{\sigma}{\sigma}$ & . & बे & $\bar{a}$ & $\begin{array}{c}\widetilde{\alpha} \\
\infty \\
0\end{array}$ & $\bar{a}$ & $\begin{array}{c}\widetilde{\alpha} \\
\infty \\
0\end{array}$ & 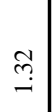 & बे. & $\stackrel{\mathscr{Z}}{-}$ & 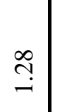 & gे & $\stackrel{0}{\circ}$ & $\stackrel{9}{=}$ & 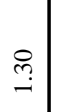 & $\begin{array}{l}\infty \\
\infty \\
0 \\
0\end{array}$ & $\stackrel{\varrho}{ت}$ & $\stackrel{\varrho}{ت}$ & 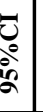 & $\stackrel{R}{i}$ \\
\hline$\frac{\bar{\Xi}}{\bar{d}}$ & $\begin{array}{l}E \\
\text { Oे } \\
\text { in }\end{array}$ & $\stackrel{\overbrace{}}{\delta}$ & $\stackrel{0}{\circ}$ & ஓ. & बे & $\begin{array}{l}\infty \\
\stackrel{0}{0}\end{array}$ & $\stackrel{\infty}{0}$ & ठे & ڤે & క. & 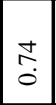 & : & $\Xi$ & 8 & $\begin{array}{l}\infty \\
\stackrel{0}{0}\end{array}$ & 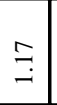 & $\stackrel{\infty}{\infty}$ & $\begin{array}{l}\infty \\
\stackrel{\infty}{0} \\
\stackrel{0}{0}\end{array}$ & $\hat{o}$ & ָิ & 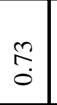 & $\stackrel{\sigma}{\sigma}$ & $\stackrel{\bullet}{-}$ & 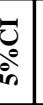 & ז. \\
\hline 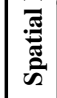 & ฮี & $\stackrel{s}{.}$ & ః̊ & à & बे & बे & 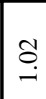 & बे & $\begin{array}{l}\infty \\
\infty \\
0 \\
0\end{array}$ & 苟 & $\begin{array}{c}\mathscr{\infty} \\
\infty \\
0\end{array}$ & مُ & $\stackrel{\text { I }}{\text { I }}$ & ֶ̆ & $\stackrel{\sigma}{\sigma}$ & $\overline{\mathfrak{T}}$ & $\bar{a}$ & $\tilde{\delta}$ & $\stackrel{\Delta}{\stackrel{\Delta}{-}}$ & $\stackrel{\sim}{\beth}$ & $\hat{\sigma}$ & $\stackrel{g}{-}$ & & 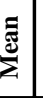 & $\underset{+}{\stackrel{I}{+}}$ \\
\hline
\end{tabular}

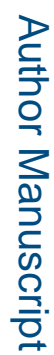

ฐ

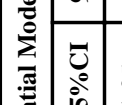

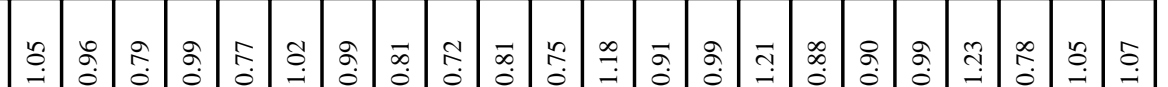

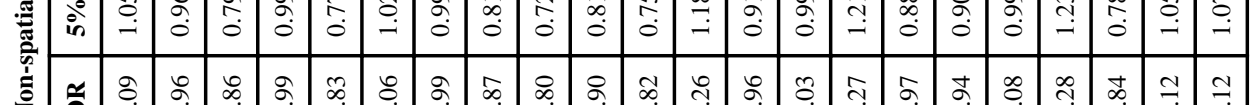

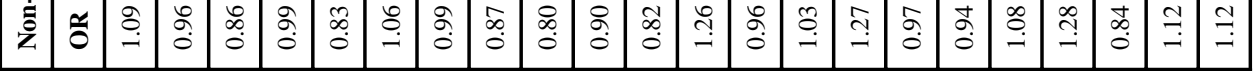

苂

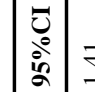

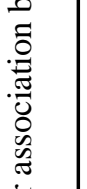

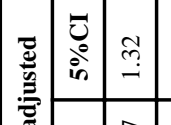

ᄒํ.

$\frac{n}{8}$

을

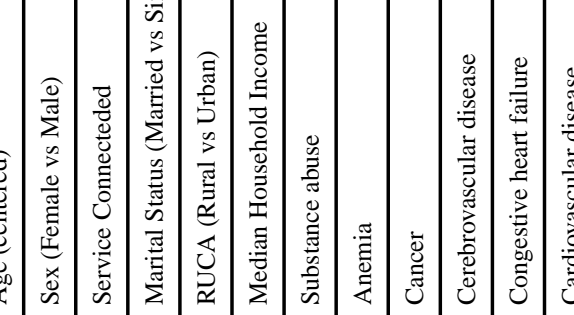

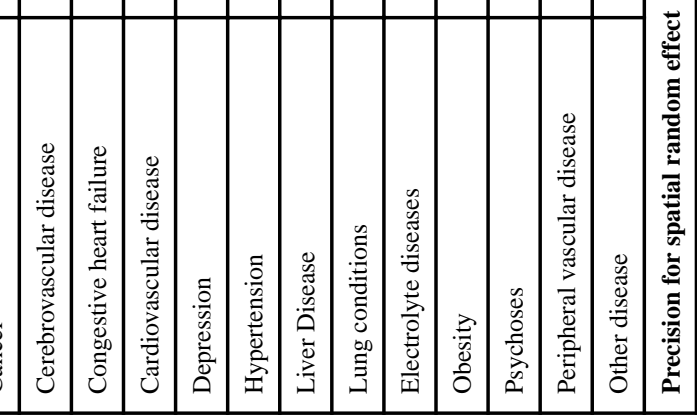

Ann Epidemiol. Author manuscript; available in PMC 2019 March 01. 